\title{
Linkage disequilibrium over short physical genomic distances measured using medium density SNP beadchip in native goat breeds of Kerala

\author{
Marykutty Thomas $^{1 *}$, G. Radhika², T.V. Aravindakshan ${ }^{3}$, R. Thirupathy ${ }^{4}$,
}

K. Raji ${ }^{5}$ and M. Shynu ${ }^{6}$.

Centre for Advanced Studies in Animal Genetics and Breeding, Kerala Veterinary and Animal Sciences University, College of Veterinary and Animal Sciences, Mannuthy, Thrissur, Kerala. PIN-680 651

Citation: Marykutty, T., Radhika, G., Aravindakshan, T.V., Thirupathy, R., Raji, K. and Shynu, M. 2021. Linkage disequilibrium over short physical genomic distances measured using medium density SNP beadchip in native goat breeds of Kerala.J. Vet. Anim. Sci.52(1): 14-18.

DOI: https://doi.org/10.51966/jvas.2021.52.1.14-18

Received: 13.06.2020

Accepted: 20.07.2020

Published: 01.01.2021

\section{Abstract}

The extent of linkage disequilibrium (LD) at genome wide level is crucial in determining the effectiveness of genomics tools in livestock breeding. The present population genomic study was conducted in native goat breeds of Kerala namely; Attapady Black goats ( $n=24)$ and Malabari goats $(n=24)$ to characterise extent of $L D$ within $40 \mathrm{kbp}$ marker interval using genome wide single nucleotide polymorphism (SNP) marker data obtained by SNP50 BeadChip genotyping. Extent of $L D$ between bi allelic markers was measured using correlation coefficient $\left(r^{2}\right)$. Mean $r^{2}$ between adjacent SNP pairs across all autosomes within 40Kbp marker interval was low (Attapady Black: 0.1336; Malabari: 0.1284$)$. The $L D$ varied across autosomes in native goats. It was the highest for SNP pairs on Capra hircus autosome $6(\mathrm{CHI} 6)$ and the lowest for SNP pairs harboured in CHI 28 in Attapady Black goats and for SNP pairs in CHI 29 in Malabari goats. The low LD estimates indicate the genetically diverse nature of native goats. Current results also imply that denser SNP beadchip array with inter marker interval of below $40 \mathrm{kbp}$ would be desirable for effective genome wide association study (GWAS) and genomic selection in native goats.

Keywords: Linkage disequilibrium, goat, SNP BeadChip

The goat is an important farm animal genetic resource of Kerala, constituting 45.56 per cent of its total livestock population (Government of India, 2014). Recently, the advent of draft reference goat genome, coupled with the introduction of single nucleotide polymorphism (SNP)

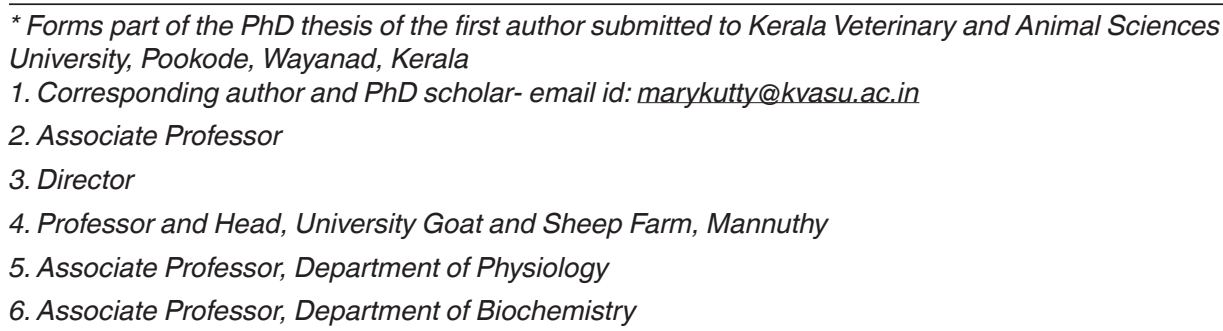

Copyright: (c) 2021 Marykutty et al. This is an open access article distributed under the terms of the Creative Commons Attribution 4.0 International License (http://creativecommons.org/licenses/by/4.0/), which permits unrestricted use, distribution, and reproduction in any medium, provided the original author and source are credited. 
array viz., Illumina caprine 50K SNP BeadChip (Dong et al., 2013; Tosser-Klopp et al., 2014) offers unprecedented opportunities for genomic applications in goat production. The medium density caprine SNP50 BeadChip enabling cheap and fast high throughput genotyping was designed by International Goat Genome Consortium (IGGC) for global use in a wide variety of goat breeds with 53,347 SNPs distributed across genome with a median spacing of $40 \mathrm{~Kb}$ (Tosser-Klopp et al., 2014).

Linkage disequilibrium (LD) is defined as the non-random association of alleles between two loci. The utility of medium density SNP bead chip currently available for genomic applications such as genomic selection and genome wide association study (GWAS) in a population depends on the extent of LD between SNP markers in the respective population (Kijas et al., 2015). The genomic LD of native goats of Kerala was not reported earlier.

The present population genomics study was carried out in two native goat breeds of Kerala namely, Attapady Black and Malabari goats to characterise the extent of LD between SNP markers over short physical distances up to $40 \mathrm{~Kb}$ using genome wide SNP marker data generated by SNP50 BeadChip genotyping. The results of the present study could provide insights with respect to the usefulness of SNP50 BeadChip with median inter marker interval of $40 \mathrm{~kb}$ for practical application in genomic predictions among native goat population of Kerala.

\section{Materials and methods}

The study population comprised of 24 each of Attapady Black and Malabari goats sampled from farmers' herds in their breeding tracts. Genomic DNA was extracted from blood samples of goats using standard phenol chloroform method (Sambrook and Russel, 2001). The DNA of 48 samples were genotyped by Illumina goat SNP50 BeadChip. Quality control of whole genome raw SNP genotype data was performed for individuals and SNPs using the Plink V.1.9 software (Purcell et al., 2007). Individuals missing more than 10 per cent of genotypic data were removed. The SNPs that did not map to any autosomes of ARS1 caprine genome assembly (https://www.ncbi.nlm.nih. gov/assembly) and those that belonged to sex chromosomes were discarded. The SNPs of minor allele frequency of above 0.05 , SNP call rate of $\geq 0.90$ and Hardy Weinberg equilibrium exact test $P$-value above the threshold level of 0.001 were only retained for downstream analysis.

Extent of LD between bi allelic markers was measured using correlation coefficient $\left(\mathrm{r}^{2}\right)$. For a single pair of loci, $A$ and $B$ with a pair allele $A 1$ and $A 2$ at locus $A$ and $B 1$ and $B 2$ at locus $B$, correlation coefficient $\left(\mathrm{r}^{2}\right)$ was computed as proposed by Hill and Robertson (1968)

$$
r^{2}=\frac{D^{2}}{f(A 1) f(A 2) f(B 1) f(B 2)}
$$

Where $D=f(A 1 B 1) f(A 2 B 2)-f(A 1 B 2) f(A 2 B 1)$ and $f(A 1 B 1), f(A 2 B 2), f(A 1 B 2)$ and(A2B1)are haplotype frequencies of $A 1 B 1, A 2 B 2, A 1 B 2$ and $A 2 B 1$ respectively; $f(A 1), f(A 2), f(B 1), f(B 2)$ are allele frequencies of $A 1, A 2, B 1$ and $B 2$ respectively.

For each breed, extent of LD $\left(r^{2}\right)$ for each pair of adjacent SNPs within $40 \mathrm{~Kb}$ marker intervals was calculated. Analysis was done in Plink V1.9 (Purcell et al., 2007).

\section{Results and discussion}

Overall LD and autosome wise LD estimate for SNPs within $40 \mathrm{~kb}$ interval in Attapady Black and Malabari goats are given in Table 1. Mean $\mathrm{r}^{2}$ between adjacent SNP across all autosomes within $40 \mathrm{~Kb}$ marker interval was 0.1336 and 0.1284 for Attapady Black and Malabari goats respectively.

The present study quantified LD of native goat breeds of Kerala utilising $r^{2}$ measure. It is a more robust LD measure when compared to the other LD measures (Ardlie et al., 2002; Kijas et al., 2014). At 40 Kb marker interval, the LD estimate of the native goats of Kerala was lower than that reported for important international trans-boundary goat breeds like Alpine, Boer, Nubian, Saanen and Toggenburg but comparable to that of regional goat breeds like Australian Rangeland (Brito et al., 2015). Finite population size and intense 
Table 1. Average linkage disequilibrium (LD, $\left.r^{2}\right)$ in different autosomal chromosomes for Single nucleotide polymorphisms (SNP) pairs within $40 \mathrm{~kb}$ interval in Attapady Black and Malabari goats of Kerala.

\begin{tabular}{|c|c|c|c|c|}
\hline \multirow{2}{*}{ Chromosome } & \multicolumn{2}{|c|}{ Attapady Black } & \multicolumn{2}{c|}{ Malabari } \\
\cline { 2 - 5 } & Number of SNP pairs & $\mathrm{r}^{2}$ & Number of SNP pairs & $\mathrm{r}^{2}$ \\
\hline 1 & 1137 & 0.1320 & 1190 & 0.1309 \\
\hline 2 & 1022 & 0.1373 & 1045 & 0.1136 \\
\hline 3 & 758 & 0.1403 & 799 & 0.1434 \\
\hline 4 & 906 & 0.1304 & 957 & 0.1287 \\
\hline 5 & 701 & 0.1307 & 738 & 0.1246 \\
\hline 6 & 952 & 0.2004 & 1034 & 0.1946 \\
\hline 7 & 743 & 0.1473 & 782 & 0.1370 \\
\hline 8 & 834 & 0.1301 & 866 & 0.1309 \\
\hline 9 & 619 & 0.1147 & 638 & 0.1071 \\
\hline 10 & 758 & 0.1205 & 759 & 0.1142 \\
\hline 11 & 674 & 0.1249 & 727 & 0.1231 \\
\hline 12 & 597 & 0.1474 & 661 & 0.1386 \\
\hline 13 & 604 & 0.1501 & 627 & 0.1473 \\
\hline 14 & 657 & 0.1485 & 690 & 0.1409 \\
\hline 15 & 556 & 0.1534 & 604 & 0.1380 \\
\hline 16 & 533 & 0.1405 & 559 & 0.1307 \\
\hline 17 & 494 & 0.1306 & 521 & 0.1197 \\
\hline 18 & 432 & 0.1091 & 445 & 0.1085 \\
\hline 19 & 376 & 0.1115 & 395 & 0.1087 \\
\hline 20 & 526 & 0.1070 & 538 & 0.1090 \\
\hline 21 & 519 & 0.1213 & 540 & 0.1120 \\
\hline 22 & 386 & 0.1182 & 414 & 0.1213 \\
\hline 23 & 366 & 0.1196 & 378 & 0.1202 \\
\hline 24 & 486 & 0.1149 & 508 & 0.1208 \\
\hline 25 & 287 & 0.1250 & 287 & 0.1064 \\
\hline 26 & 334 & 0.1330 & 359 & 0.1296 \\
\hline 27 & 347 & 0.1157 & 354 & 0.1097 \\
\hline 28 & 339 & 0.1003 & 365 & 0.1053 \\
\hline 29 & 314 & 0.1133 & 314 & 0.0991 \\
\hline$A l l$ & 17257 & 0.1336 & 18094 & 0.1284 \\
\hline
\end{tabular}

selection undergone by improved breeds during breed formation and improvement are implicated for high genomic LD in most of the modern-day livestock breeds (Hayes, 2007). The low genomic LD in native goats indicates the diverse nature of these goat breeds.

The information about the LD among adjacent markers in the genome of native goats has practical consequences for genomic applications and predictions. The $r^{2}$ values of 0.2 and 0.3 are important indicators determining effectiveness of accuracy of genomic selection and effectiveness of association studies respectively (Meuwissen et al., 2001; Ardlie et al., 2002). The $r^{2}$ of 0.13 even at a short chromosomal distance of $40 \mathrm{~kb}$ in native goats of Kerala clearly indicates limited application of current 50K SNP panel available, for genomic selection and GWAS in native breeds of Kerala. Alternatively, more denser SNP bead array with inter marker interval of below $40 \mathrm{~kb}$ would be required to capture LD information needed for implementing genomic selection with reasonable accuracy in native goat breeds of Kerala.

The LD varied across autosomes in native goats (Table 1 ). The $r^{2}$ estimate was the highest for Capra hircus autosome $6(\mathrm{CHI}$ 6) (Attapady Black: 0.20; Malabari: 0.19). Nevertheless, it was the lowest for SNP pairs harboured in $\mathrm{CHI} 28$ in Attapady Black goats and for SNP pairs in $\mathrm{CHI} 29$ in Malabari goats. 
Marked inter chromosomal heterogeneity in LD detected in the present study is in support of the observations of Mdladla et al. (2016) in South African goats. Selection could result in inter chromosomal heterogeneity in LD (Biegelmeyer et al., 2016). Hence, higher LD estimates detected in $\mathrm{CHI} 6$ of native goat breeds compared to other autosomes could be suggestive of the presence of common genomic region influencing traits that have been under selection in both breeds. Evidence of genomic regions spanning in $\mathrm{CHI} 6$ influencing adaptation to hot arid environment has been reported in goats (Kim et al., 2015). Both native goat breeds of Kerala are well known for their adaptation to humid tropical stressors of Kerala.

\section{Conclusion}

This population genomics study characterised the extent of LD between genetic markers at short marker intervals among native goat breeds of Kerala using high throughput genomic data obtained by goat SNP50 BeadChip genotyping. The LD $\left(r^{2}\right)$ between adjacent SNPs across all autosomes was low and this result was contrary to the findings in modern breeds of livestock that displayed high LD due to factors like low $\mathrm{Ne}$ and intense selection.

\section{Acknowledgements}

This work was partially funded by Animal Husbandry Department, Kerala. We thank ICAR-AICRP on goat improvement programme (Malabari) for the facilities and financial support provided for the collection of samples

\section{References}

Ardlie, K.G., Kruglyak, L. and Seielstad M. 2002. Patterns of linkage disequilibrium in the human genome. Nat. Rev. Genet. 3:299-309.

Biegelmeyer, P., Gulias-Gomes, C. C., Caetano, A. R., Steibel, J. P.and Cardoso, F. F.2016. Linkage disequilibrium, persistence of phase and effective population size estimates in Hereford and Braford cattle. BMC Genet. 17:32
Brito, L.F., Jafarikia, M., Grossi, D.A., Kijas, J.W., Porto-Neto, L.R., Ventura, R.V., Salgorzaei, M. and Schenkel, F.S. 2015. Characterization of linkage disequilibrium, consistency of gametic phase and admixture in Australian and Canadian goats. BMC Genet. 16:1.

Dong, Y., Xie, M., Jiang, Y., Xiao, N., Du, X., Zhang, W., Tosser-Klopp G., Wang, J., Yang, S., Liang, J., Chen, J., Zeng, P., Hou, Y., Bian, C., Pan, S., Li, Y., Liu, X., Wang, W., Servin, B., Sayre, B., Zhu, B., Sweeney, D., Moore, R., Nie, W., Shen, Y., Zhao, R., Zhang, R., Li, J., Faraut, T., Womack, J., Zhang, Y., Kijas, J., Cockett, N., Xu, X., Zhao, S., Wang, J. and Wang, W. 2013. Sequencing and automated whole genome optical mapping of the genome of a domestic goat (Capra hircus). Nat. Biotechnol.31:135-141.

Government of India. 2014. 19th livestock census-2012. All India report. pp.78.

Hill, W. G. and Robertson, A. 1968. Linkage disequilibrium in finite populations. Theor. Appl. Genet. 38:226-231.

Hayes, B. 2007. QTL mapping, MAS and genomic selection. A short-course organized by Animal Breeding and Genetics. Department of Animal Science, lowa State University.179pp.

Kijas, J. W., Porto-Neto, L., Dominik, S., Reverter, A., Bunch, R., Mcculloch, R., Hayes, B.J., Brauning, R., McEwan, J. and the International Sheep Genomics Consortium.2014.Linkagedisequilibrium over short physical distances measured in sheep using a high-density SNP chip. Anim. Genet. 45: 754-757.

Kim, E.S., Elbeltagy, A.R., Aboul-Naga, A.M., Rischkowsky, B., Sayre, B., Mwacharo, J.M. and Rothschild, M. F. 2015. Multiple genomic signatures of selection in goats and sheep indigenous to a hot arid environment. Heredity. 10:1-10.

Meuwissen, T. H., Hayes, B. J. and Goddard, M. E. 2001. Prediction of total genetic 
value using genome-wide dense marker maps. Genetics 157:1819-1829.

Mdladla, K., Dzomba, E.F., Huson, H.J. and Muchadeyi, F.C. 2016. Population genomic structure and linkage disequilibrium analysis of South African goat breeds using genome-wide SNP data. Anim. Genet. 47:471-482.

Purcell, S., Neale, B., Todd-Brown, K., Thomas, L., Ferreira, M.A.R., Bender, D., Maller, J., Sklar, P., de Bakker, P.I.W., Daly, M.J. and Sham, P.C. 2007. PLINK: a toolset for whole-genome association and population-based linkage analysis. Am. J. Hum. Genet. 81(3):559-575.

Sambrook, J. and Russell, D.W.2001. Molecular Cloning: A laboratory manual. 3rd Ed,
Cold Spring Harbor Laboratory Press, New York. 2100.

Tosser-Klopp, G., Bardou, P., Bouchez, O., Cabau, C., Crooijmans, R., Dong, Y., Donnadieu-Tonon, C., Eggen, A., Heuven, H.C., Jamli, S., Jiken, A. J., Klopp, C., Lawlet, C.T., McEwan, K., Martin, P., Moreni, C.R., Mulsant, P., Nabihoudine, I., Pailhoux, E., Palhière, I., Rupp, R., Sarry, J., Sayre, B.L., Tircazes, A., Wang, J., Wang, W., Zhang, W. and International Goat Genome Consortium. 2014. Design and characterization of a 52 K SNP chip for goats. PLoS one. 9: e86227. 